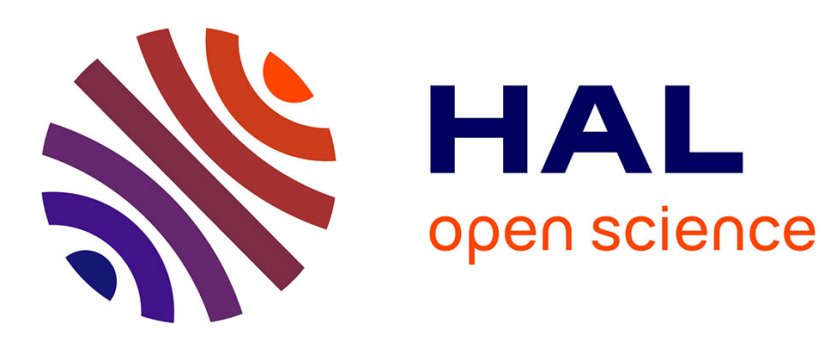

\title{
Wetting transition for a thin cylinder
}

\author{
P. Levinson, J. Jouffroy, F. Brochard
}

\section{To cite this version:}

P. Levinson, J. Jouffroy, F. Brochard. Wetting transition for a thin cylinder. Journal de Physique Lettres, 1985, 46 (1), pp.21-26. 10.1051/jphyslet:0198500460102100 . jpa-00232471

\section{HAL Id: jpa-00232471 https://hal.science/jpa-00232471}

Submitted on 1 Jan 1985

HAL is a multi-disciplinary open access archive for the deposit and dissemination of scientific research documents, whether they are published or not. The documents may come from teaching and research institutions in France or abroad, or from public or private research centers.
L'archive ouverte pluridisciplinaire HAL, est destinée au dépôt et à la diffusion de documents scientifiques de niveau recherche, publiés ou non, émanant des établissements d'enseignement et de recherche français ou étrangers, des laboratoires publics ou privés. 
Classification

Physics Abstracts

$68.10-68.45$

\title{
Wetting transition for a thin cylinder
}

\author{
P. Levinson, J. Jouffroy and F. Brochard - \\ Collège de France, Physique de la Matière Condensée, 11, Place Marcelin Berthelot, \\ 75231 Paris Cedex 05, France
}

(Reçu le 2 juillet 1984, accepté le 6 novembre 1984)

Résumé. - Un cylindre de rayon $b$ immergé dans un mélange binaire A/B produit deux effets : (1) adsorption préférentielle de A, décrite par un champ de surface $h_{1} ;(2)$ réduction des interactions $\mathrm{A} / \mathrm{B}$ près de la paroi (négligée ici). En utilisant la théorie de champ moyen de Cahn, on trouve que le mouillage parfait apparaît seulement pour des cylindres de rayon $b>b_{c}\left(h_{1}\right)$. Près du point critique de démixtion, on trouve un mouillage du cylindre pour des températures $T>T_{\mathrm{w}}\left(b, h_{1}\right)$. A $T_{\mathrm{w}}$, la transition est du $1^{\mathrm{er}}$ ordre. Elle devient du $2^{\mathrm{e}}$ ordre pour $b=b_{\mathrm{c}}$.

Abstract. - A cylinder of radius $b$ immersed in a two fluid binary mixture A/B produces two effects : (1) preferential adsorption of A, described by a surface field $h_{1} ;(2)$ reduction of $\mathrm{A} / \mathrm{B}$ interactions near the wall (neglected here). Using the Cahn mean-field theory [1], we find that perfect wetting occurs only for cylinders of radius $b>b_{c}\left(h_{1}\right)$. Then near the critical point, wetting is found at temperatures $T>T_{\mathrm{w}}\left(b, h_{1}\right)$. At $T_{\mathrm{w}}$ the transition is first order. It becomes second order when $b=b_{\mathrm{c}}$.

\section{Introduction.}

The wetting transition has been extensively studied for plane walls both theoretically [2, 3] and experimentally $[4,5]$. Our purpose is to study the case of cylinders which are of both fundamental and practical interest. The wetting of fibers has industrial applications (textile, dyeing, ink...). One can obtain fibers which radii range from several angströms up to macroscopic dimensions.

For thick fibers, we must recover the classical $2 \mathrm{~d}$ behaviour first studied by Cahn [1]. In the simplest model, the effect of the wall just introduces a localized field $h_{1}$ describing preferential adsorption. We neglect long range van der Waals forces [6] and the shift of $A / B$ critical temperature induced by the wall [2].

The free energy (per surface site) of the semi-infinite fluid in contact with a planar surface is given by

$$
\left.\frac{\Delta F}{k T}\right|_{\text {site }}=-h_{1} M_{\mathrm{S}}+\int_{0}^{\infty}\left[\frac{1}{a} \Delta U+\frac{a}{2}(\nabla M)^{2}\right] \mathrm{d} Z
$$

where $M$ is a composition variable $\left(M=\phi_{\mathrm{A}}-\phi_{\mathrm{c}}\right), a$ is a molecular size and 
$\Delta U=U(M)-U\left(-M_{0}\right)$, with

$$
U=-\frac{1}{2} M^{2} \frac{a^{2}}{\xi^{2}}+\frac{1}{4} M^{4}
$$

$\left(-M_{0}\right)$ is the equilibrium composition at infinity $\left(M_{0}=\frac{a}{\xi}\right)$ and $\xi=\frac{a}{\sqrt{\frac{T_{\mathrm{c}}-T}{T_{\mathrm{c}}}}}$ is the correlation length.

The minimum of $\Delta F$ occurs when

$$
\frac{\mathrm{d}^{2} M}{\mathrm{~d} Z^{2}}=-\frac{M}{\xi^{2}}+\frac{M^{3}}{a^{2}}
$$

with the boundary condition at $Z=0$

$$
-h_{1}=a \frac{\mathrm{d} M}{\mathrm{~d} Z} .
$$

Equation (3) describes the motion of a particle in a potential $-U(M)$. From (3) and (4) one derives the surface composition $M_{\mathrm{S}}$ :

$$
h_{1}=2 \sqrt{\frac{1}{2} \Delta U\left(M_{\mathrm{S}}\right)} .
$$

In reduced units $\frac{M}{M_{0}}=u$ and $\frac{Z}{\xi}=X$, equation (5) leads to

$$
\sqrt{2} h_{1} \frac{\xi^{2}}{a^{2}}=\left|u_{\mathrm{s}}^{2}-1\right|
$$

As shown in figure 1, equation (6) has one or three solutions a, b, c. The stable solution corres-

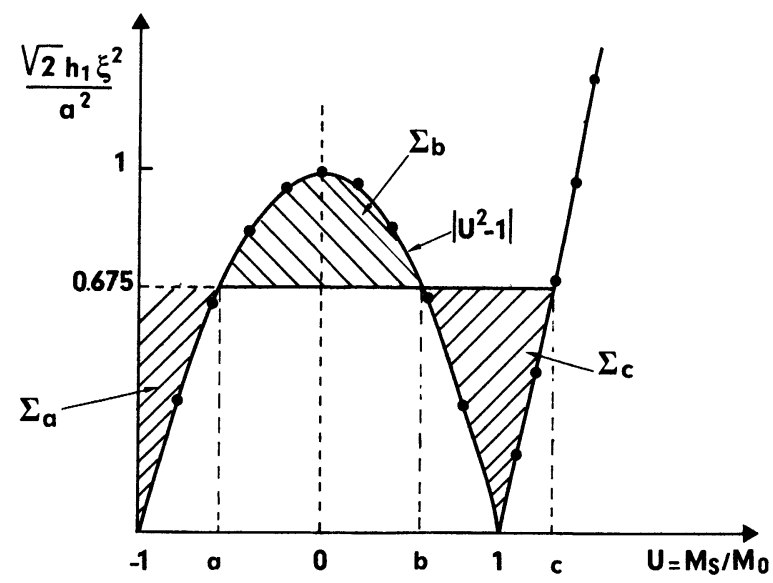

Fig. 1. - Graphic representation of the surface free energy according to Eq. (7'). The bulk fluid composition corresponds to $u=-1$. The surface composition is given by the intersection of horizontal lines $y=\frac{\sqrt{2} h_{1} \xi^{2}}{a^{2}}$ with the curve $\left|u^{2}-1\right|$ (Eq. (5)). If $y<0.675$, a is the stable root. If $y>0.675$, $\mathrm{c}$ is the stable root. If $y=0.675\left(\Sigma_{\mathrm{b}}=\Sigma_{\mathrm{c}}\right)$ there is a first order transition form at $\mathrm{c}$. 
ponds to $\sigma=\Delta F_{\min }$. The surface free energy, $\sigma$, can be written as :

$$
\begin{aligned}
\frac{\sigma}{k T} & =+h_{1} M_{0}+\int_{-M_{0}}^{M_{\mathrm{s}}}\left[-h_{1}+2 \sqrt{\frac{\Delta U}{2}} \mathrm{~d} M\right] \\
\text { i.e., } \quad & \frac{\sigma}{M_{0} k T}=h_{1}+\int_{-1}^{u_{\mathrm{s}}}\left[-h_{1}+\frac{a^{2}}{\sqrt{2} \xi^{2}}\left|u^{2}-1\right|\right] \mathrm{d} u .
\end{aligned}
$$

For the roots a, b, c of equation (6), one finds $\sigma_{\mathrm{a}}-\sigma_{0}=k\left(-\Sigma_{\mathrm{a}}\right), \sigma_{\mathrm{b}}-\sigma_{0}=k\left(\Sigma_{\mathrm{b}}-\Sigma_{\mathrm{a}}\right)$ and $\sigma_{\mathrm{c}}-\sigma_{0}=k\left(\Sigma_{\mathrm{b}}-\Sigma_{\mathrm{a}}-\Sigma_{\mathrm{c}}\right)$, where $\Sigma_{i}$ are the surfaces defined in figure 1. $\mathrm{b}$ corresponds to a maximum. At large $\xi$, near the critical point, $\mathrm{c}$ is the stable solution (perfect wetting). At low $\xi$, a is the stable solution (partial wetting). For $\xi=\xi_{\mathrm{w}}$ (i.e., $T=T_{\mathrm{w}}$ ) we have a first order transition from partial to perfect wetting. $\xi_{\mathrm{w}}$ is defined by $\Sigma_{\mathrm{b}}=\Sigma_{\mathrm{c}}$. It corresponds to $\sqrt{2} h_{1} \frac{\xi_{\mathrm{w}}^{2}}{a^{2}}=$ 0.675, i.e., $h_{1} \frac{\xi_{\mathrm{w}}^{2}}{a^{2}}=2.09$. The plot of $\frac{M_{\mathrm{S}}}{M_{0}}$ versus $h_{1} \frac{\xi^{2}}{a^{2}}$ is represented in figure 1 .

\section{Wetting of cylinders.}

In the cylindrical geometry, the minimum of $\Delta F$ is given by

$$
a^{2}\left[\frac{\partial^{2} M}{\partial r^{2}}+\frac{1}{r} \frac{\partial M}{\partial r}\right]=-M \frac{a^{2}}{\xi^{2}}+M^{3}
$$

with boundary conditions

$$
-h_{1}=\left.a \frac{\partial M}{\partial r}\right|_{r=b} \quad M_{\infty}=-M_{0} .
$$

In reduced units $M=M_{0} u$ and $r=\xi X$, equations (8) and (9) are written as

$$
\begin{gathered}
\frac{\mathrm{d}^{2} u}{\mathrm{~d} X^{2}}+\frac{1}{X} \frac{\mathrm{d} u}{\mathrm{~d} X}=-u+u^{3} \\
\left.\frac{\mathrm{d} u}{\mathrm{~d} X}\right|_{X=X_{\mathrm{b}}}=-h_{1} \frac{\xi^{2}}{a^{2}} \text { or }\left.X^{2} \frac{\mathrm{d} u}{\mathrm{~d} X}\right|_{X=X_{\mathrm{b}}}=-h_{1} \frac{b^{2}}{a^{2}}=-S \\
u(\infty)=-1 .
\end{gathered}
$$

These equations have been solved numerically. We know a one parameter manifold of solutions for $X \rightarrow \infty$,

$$
u=-1+\frac{\mathrm{e}^{-\sqrt{2}(X-\alpha)}}{\sqrt{X}}
$$

We start from a value $X_{0}$ of $X$. We calculate $\alpha$ to satisfy $1-u\left(X_{0}, \alpha\right)<10^{-3}$. We integrate equation (8) and we draw the profiles $u(X, \alpha)$. Then we fix a value $X_{\mathrm{b}}$ of $X$ and we calculate $u\left(X_{\mathrm{b}}, \alpha\right)$ and $S=-\left.X_{\mathrm{b}}^{2} \frac{\mathrm{d} u(\alpha)}{\mathrm{d} X}\right|_{X_{\mathrm{b}}}$. We then plot $u\left(X_{\mathrm{b}}\right)$ versus $S$ (Fig. 2). We find three different behaviours depending upon the value of $X$ with respect to $X_{c} \simeq 1.8( \pm 0.1):(1)$ for $X_{b}>X_{c}$, there is an S shaped curve (Fig. 2a), i.e. a first order transition for $S=S_{\mathrm{c}}\left(X_{\mathrm{b}}\right) . S_{\mathrm{c}}\left(X_{\mathrm{b}}\right)$ is deter- 


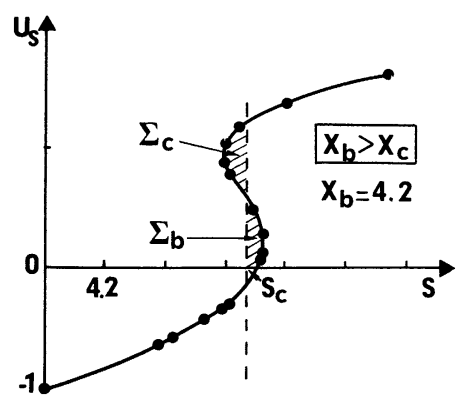

a)

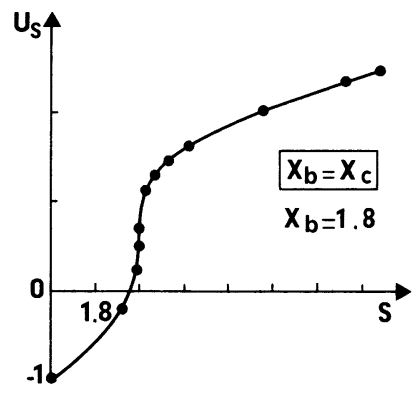

b)

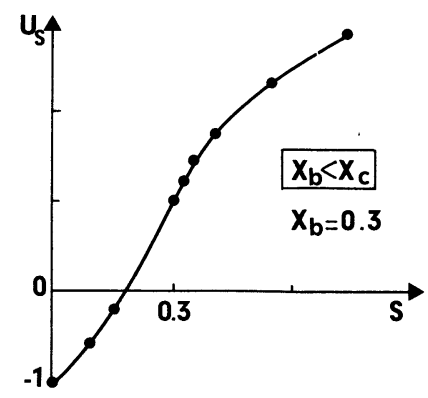

c)

Fig. 2. - Composition at the surface of the cylinder versus $S=h_{1} \frac{b^{2}}{a^{2}}$ for three reduced radii $X_{\mathrm{b}}=\frac{b}{\xi}$ : (a) for large cylinders $\left(X_{\mathrm{b}}>X_{\mathrm{c}}\right)$, we find a first order wetting transition for $S=S_{\mathrm{c}}\left(\Sigma_{\mathrm{b}}=\Sigma_{\mathrm{c}}\right)$. (b) for $X_{\mathrm{b}}=X_{\mathrm{c}}$, the wetting transition becomes second order. (c) for thin cylinders $\left(X_{\mathrm{b}}<X_{\mathrm{c}}\right)$, there is no wetting transition.

mined by the equality of the areas $\Sigma_{\mathrm{b}}$ and $\Sigma_{\mathrm{c}}$ (2) for $X_{\mathrm{b}}<X_{\mathrm{c}}$, there is no inflexion, i.e. no wetting transition (Fig. 2c). (3) for $X_{\mathrm{b}}=X_{\mathrm{c}}$, there is a second order critical point of wetting.

The critical temperature $T_{\mathrm{w}}\left(b, h_{1}\right)$ is represented in figure 3. $T_{\mathrm{w}}$ is defined by $\frac{a^{2}}{h_{1} \xi_{\mathrm{w}}^{2}}=\frac{X_{\mathrm{b}}^{2}}{S_{\mathrm{c}}}$ and $\frac{a^{2}}{h_{1} b^{2}}$ equals $\frac{1}{S_{\mathrm{c}}}$. The curve $\frac{a^{2}}{h_{1} \xi_{\mathrm{w}}^{2}}$ versus $\frac{a^{2}}{h_{1} b^{2}}$ ends up at a second order critical point :

$$
\left\{\begin{array}{l}
\frac{a^{2}}{h_{1} b_{\mathrm{c}}^{2}}=0.17 \\
\frac{a^{2}}{h_{1} \xi_{\mathrm{wc}}^{2}}=\frac{T_{\mathrm{c}}-T_{\mathrm{wc}}}{h_{1} T_{\mathrm{c}}}=0.86 .
\end{array}\right.
$$

Typically $\frac{T_{\mathrm{c}}-T_{\mathrm{w}}}{T_{\mathrm{c}}}$ for a plane is of the order of 0.03 , i.e., $h_{1} \simeq 5 \times 10^{-2}$. This leads to $\frac{b_{\mathrm{c}}}{a} \simeq 10$.

It should be noticed that for cylinders the thickness $z_{w}$ of the wetting layer is finite, whereas it diverges for a plane surface. For both cases, the first order wetting transition is due to a competition between the two minima of the free energy versus $z_{w}$. For the plane, one minimum is at finite $z_{\mathrm{w}}$ and the other is at infinite $z_{\mathrm{w}}$. For cylinders, both minima are at finite $z_{\mathrm{w}}$. The corresponding composition profiles are shown in figure 4 for the case $X_{\mathrm{b}}=4.2$ (Fig. 2a), i.e. $\frac{b}{a} \sim 16$. The wetting thickness is of the order of $\xi$, i.e. several angströms.

\section{Conclusion.}

Using the most simple description of wetting, we find that a wetting transition appears only for cylinders larger than a critical radius $b_{c}$. This result could possibly be tested by studying the preferential adsorption on a rigid gel of rods of variable size (agarose, collagen, fibrinogen, lectin) swollen by a A/B binary mixture. Even if $z_{\mathrm{w}}$ is a microscopic length, the surface per unit volume for these systems can be very large and the measured effect can be significant. 


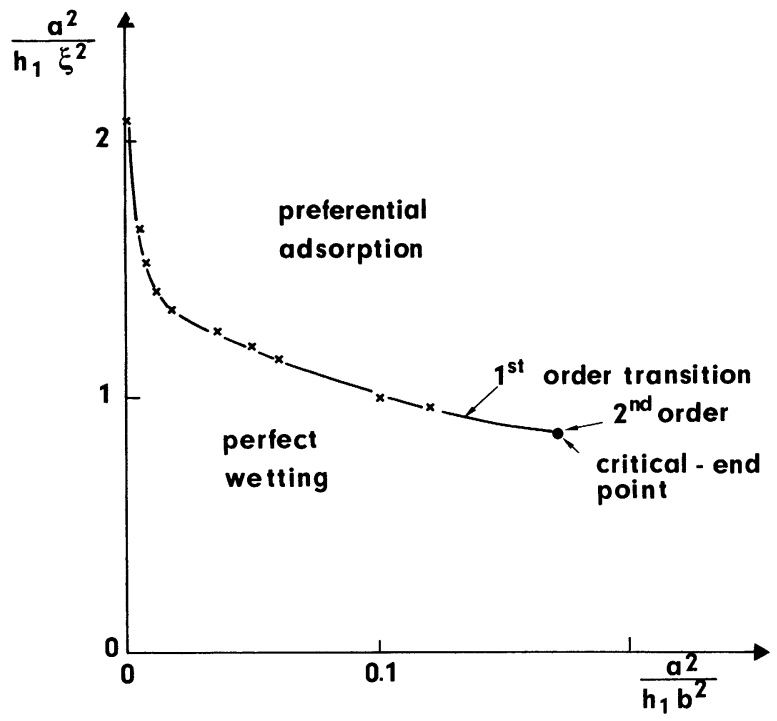

Fig. 3. - Plot of the wetting transition temperature $\left(\frac{a^{2}}{h_{1} \xi^{2}}=\frac{T_{\mathrm{c}}-T_{\mathrm{w}}}{h_{1} T_{\mathrm{c}}}\right)$ versus $\frac{a^{2}}{h_{1} b^{2}}$. The first order transition line ends at a second-order transition.

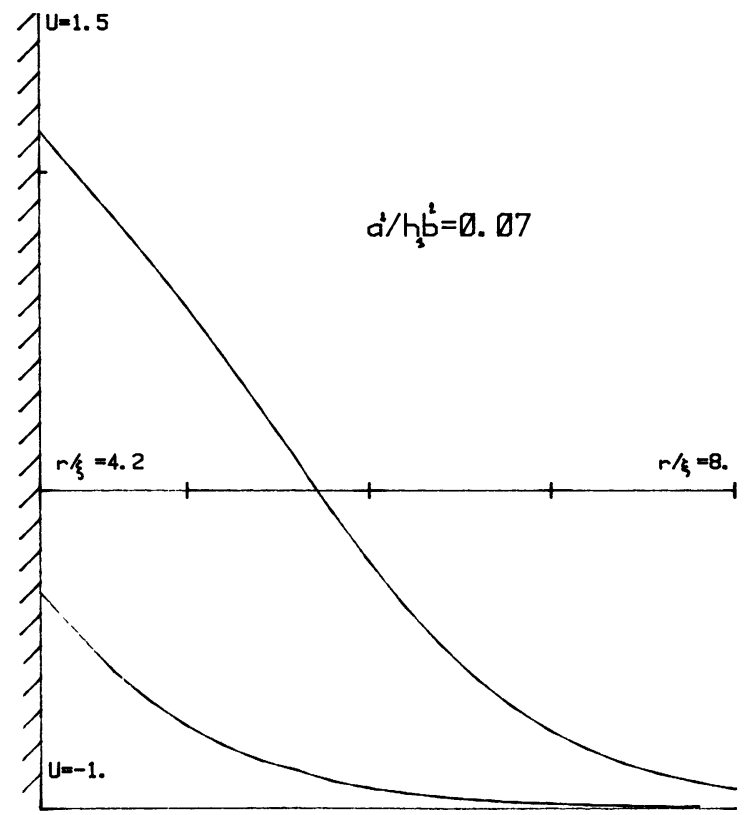

Fig. 4. - Composition profiles just above and below the wetting transition. 


\section{References}

[1] Cahn, J. W., J. Chem. Phys. 66 (1977) 3667.

[2] Pandit, R. and Wortis, M., Phys. Rev. B 25 (1982) 3226.

[3] Brezin, E., Halperin, B. and Leibler, S., J. Physique 44 (1983) 775.

LeIBLER, S., Thesis, Paris (1984).

[4] Pohl, D. and Goldburg, W., Phys. Rev. Lett. 48 (1982) 1111.

[5] Teletzke, G., Scriven, L. and Davis, H., J. Chem. Phys. 78 (1983) 1431.

[6] De Gennes, P. G., C.R. Hebd. Séan. Acad. Sci. Paris 297 (1983) 9. 